\title{
DETERMINAÇÃO DO PERFIL DOS USUÁRIOS E DA COMPOSIÇÃO QUÍMICA E NUTRICIONAL DA ALIMENTAÇÃO OFERECIDA NO RESTAURANTE UNIVERSITÁRIO DA UNIVERSIDADE ESTADUAL PAULISTA, ARARAQUARA, BRASIL
}

\section{DETERMINATION OF THE USERS' PROFILE AND OF THE CHEMICAL AND NUTRITIONAL COMPOSITION OF THE MEALS OFFERED AT THE UNIVERSITY RESTAURANT OF THE "UNIVERSIDADE ESTADUAL PAULISTA", ARARAQUARA, BRAZIL}

\author{
Maria Arlene FAUSTO' \\ José Armando ANSALONI' \\ Marcelo Eustáquio SILVA' \\ Jair GARCIA JÚNIOR' \\ Akeber Abou DEHN' \\ Thaís Borges CÉSAR²
}

RESUMO

\begin{abstract}
Este estudo teve como objetivos determinar o perfil e o estado nutricional da clientela e a composição química e nutricional das refeições oferecidas no restaurante universitário da Universidade Estadual Paulista de Araraquara, Brasil. Realizou-se a determinação química do teor de proteínas, lipídios, carboidratos, fibra, cinzas e umidade de amostras das refeições fornecidas. A amostra populacional foi constituída de 403 usuários (212 mulheres e 191 homens). Em relação ao perfil do usuário, constatou-se que 82,60\% encontravam-se na faixa etária de 18 a 25 anos e 75,44\% dos indivíduos apresentaram índice de massa corporal dentro da faixa de normalidade. Em média, as refeições continham 4,74\% de proteínas, 10,84\% de lipídeos, 24,32\% de carboidratos, 3,30\% de fibras, 1,00\% de cinzas e 55,00\% de umidade. Os dados mostraram que as refeições do restaurante universitário continham excesso de proteínas e de energia e que se faz necessário realizar ajustes na sua composição para adequá-la ao perfil da clientela atendida.
\end{abstract}

Termos de indexação: avaliação nutricional, dietética, antropometria, composição química, proteínas, caloria, estudantes.

\begin{abstract}
This study aimed at determining the clientele's profile and nutritional status and the chemical composition of the meals offered at the university restaurant of University Estadual Paulista, Araraquara, Brazil. For checking these aspects, the study carried out the chemical determination of the content of proteins, lipids, carbohydrates, dietary fiber, ashes and humidity of meals samples. The population sample was comprised of 403 users (212 women and 191 men). Regarding the users' profile, it was verified that $82.6 \%$ were in the age group of 18 to 25 years and $75.44 \%$ of the individuals showed body mass index (BMI) within the range of normality. On average, the meals contained $4.74 \%$ of proteins, $10.84 \%$ of lipids, $24.32 \%$ of carbohydrates, $3.30 \%$ of fibers, $1.00 \%$ of ashes and $55.00 \%$ of humidity. The data showed that the University Restaurant meals contained proteins and calories in excess. Therefore, it is necessary to adjust this composition in order to make it suitable to the assisted clientele profile.
\end{abstract}

Index terms: nutritional assessment, dietetics, anthropometry, chemical composition, proteins, calories, students.

\footnotetext{
(1) Departamento de Alimentos, Escola de Nutrição, Universidade Federal de Ouro Preto. Campus Universitário, 35400-000, Ouro Preto. MG, Brasil. Correspondência para/Correspondence to: M.A. FAUSTO.

(2) Departamento de Alimentos e Nutrição, Faculdade de Ciências Farmacêuticas, Universidade Estadual Paulista de Araraquara.
} 


\section{INTRODUÇÃO}

Os restaurantes universitários e outros restaurantes institucionais devem fornecer refeições nutricionalmente adequadas para os seus usuários. Para realizar o planejamento da alimentação de grupos populacionais, é necessário conhecer o perfil da clientela atendida (sexo, faixa etária, o nível de atividade física, peso e altura), o seu estado nutricional e o número de refeições habitualmente consumidas por dia. Na falta dessas informações, o planejamento da alimentação acaba sendo realizado com base em estimativas do perfil da clientela, o que dificulta a avaliação do impacto nutricional da alimentação sobre os usuários, assim como a importância do restaurante para a comunidade-alvo.

$O$ restaurante universitário (RU) da Universidade Estadual Paulista (UNESP) de Araraquara, São Paulo, fornece duas refeições diárias (almoço e jantar) à comunidade universitária, durante cinco dias.

Estima-se que, no dia de maior freqüência, o RU forneça em torno de 500 refeições no horário de almoço. Durante o semestre letivo, são fornecidas, em média, 7 mil refeições por mês. Um estudo anterior (Fausto et al., 1995) identificou que os principais usuários desse restaurante eram estudantes na faixa etária de 18 a 25 anos. Este estudo, realizado durante o ano de 1995, foi conseqüência da necessidade de obtenção de maiores informações sobre a quantidade de nutrientes oferecida habitualmente nas refeições do RU, avaliar a adequação da oferta energética e protéica em relação às demandas dos usuários, bem como avaliar o seu estado nutricional por meio do Índice de Massa Corporal (IMC). Pretendeu-se, também, definir o perfil da clientela atendida com o objetivo de subsidiar o planejamento e a avaliação dietética da alimentação oferecida no local.

\section{CASUÍSTICA E MÉTODOS}

\section{Coleta de amostras das refeições}

Foram coletadas amostras das refeições oferecidas pelo RU, durante cinco dias consecutivos. Para que as amostras correspondessem ao total de alimentos habitualmente porcionados pelos funcionários, elas foram coletadas no utensílio próprio utilizado no local (bandejão), durante o horário de funcionamento do restaurante (almoço e jantar). Para evitar modificações nos cardápios ou nas quantidades de alimentos porcionados, os funcionários do local não foram informados a respeito da pesquisa.

\section{Determinação da composição química das refeições}

A determinação da composição química das amostras seguiu os padrões preconizados pela Association of Official... (1965):

Proteínas: determinada pelo método Kjeldahl.
Lipídios: o porcentual de lipídios totais foi determinado pelo método Bligh \& Dyer, utilizando o sistema duplo metanol-clorofórmio como solvente. Fibras: determinadas pelo método Fibra Detergente Ácido. Cinzas: obtidas por calcinação da matéria orgânica em forno de mufla a $550^{\circ} \mathrm{C}$ até se obter o peso constante. Carboidratos: determinados por diferença. Umidade: determinada por secagem a $105^{\circ} \mathrm{C}$ até se obter o peso constante.

\section{Amostra populacional}

A amostra populacional da pesquisa foi constituída de 403 usuários do RU (212 mulheres e 191 homens). Como é estimado que o RU forneça em torno de 500 refeições de almoço nos dias de maior freqüência, esse número corresponde a $80,6 \%$ dos usuários, aproximadamente. Os participantes foram submetidos à avaliação antropométrica de peso e altura e preencheram um questionário, que teve como objetivo o levantamento de informações sobre sexo, data de nascimento e atividade ocupacional dos usuários, bem como o número de refeições por eles consumidas naquele local. Foi distribuído aos usuários na entrada do RU, durante o horário de almoço, e, após o seu preenchimento, eram realizadas as medições de peso e altura.

As medidas de peso foram realizadas em balança eletrônica portátil Fillizola ${ }^{\circledR}$, com capacidade de 150 kg e as medidas de altura, com fitas métricas plastificadas de 1,5 m de comprimento, fixadas na parede a 1 metro do chão. Um pesquisador foi responsável pela anotação do peso e dois pesquisadores se encarregaram da coleta das medidas de altura.

A partir dos dados de peso e altura calculou-se o índice de massa corporal (IMC) dos indivíduos. Os limites de corte utilizados para o IMC foram aqueles adotados pela Organização Mundial de Saúde para uso internacional (World Health..., 1995). Os dados obtidos foram processados e analisados com o auxílio do Software Epi Info 5.01.

\section{Determinação da recomendação de ingestão energética e protéica para os usuários do restaurante universitário}

A determinação do Gasto Energético Total (GET) dos usuários do RU foi realizada utilizando o método da Recommend Dietary Allowances (RDA) de 1989 (National Research..., 1989), considerando dois níveis de atividade física (leve e moderada) para ambos os sexos. A recomendação de ingestão protéica foi calculada utilizando-se o valor de $0,91 \mathrm{~g} / \mathrm{kg} / \mathrm{dia}$, determinado a partir da recomendação da Food and Agriculture Organization, e corrigida de acordo com a digestibilidade protéica da dieta mista brasileira (Food and Agriculture..., 1985). O cálculo do GET e da recomendação protéica foi realizado utilizando-se o peso médio observado dos usuários do RU, para a faixa etária de 18 a 25 anos. 


\section{RESULTADOS}

\section{Perfil e estado nutricional dos usuários}

Dentre os usuários que preencheram o item do questionário correspondente ao número de refeições consumidas no RU por semana $(n=399)$, observou-se que a maioria dos indivíduos encontra-se na faixa de consumo de 1 a 6 refeições por semana. Na faixa de consumo de 7 a 10 refeições por semana se observou um predomínio dos indivíduos entre 20 e 25 anos (77,55\%) (Tabela 1$)$.

Ao se avaliar a distribuição do IMC de acordo com o número de refeições consumidas por semana (Tabela 1), constatou-se que $83,67 \%$ dos indivíduos que utilizam o RU como o principal local para a realização das grandes refeições (almoço e jantar) - indicado por um consumo entre 7 e 10 refeições/semana - apresentam o IMC dentro da faixa de normalidade. Quanto aos usuários que consomem de 1 a 6 refeições/semana, 74,28\% encontram-se com o IMC dentro da faixa de normalidade e 13,43\% apresentam baixo peso (IMC $<18,5)$.
Na Tabela 2 encontram-se os dados médios de peso e altura dos usuários do RU, de acordo com a faixa etária e o sexo.

\section{Adequação das refeições quanto às recomendações de consumo de nutrientes}

$\mathrm{Na}$ Tabela 2 encontram-se os dados de taxa metabólica basal, GET e recomendação de ingestão protéica para os usuários do RU de 18 a 25 anos, para ambos os sexos. A recomendação de ingestão energética diária média para os indivíduos do sexo feminino variou de $1928 \mathrm{Kcal}$ a $2096 \mathrm{Kcal}$ e a de ingestão protéica, de 48,68 g a 50,41 g. A recomendação de ingestão energética diária média para os indivíduos do sexo masculino variou de 2792 Kcal a 3047 Kcal e a de ingestão protéica, de $65,43 \mathrm{~g}$ a $66,25 \mathrm{~g}$.

As refeições se compuseram basicamente de arroz, feijão, salada (vegetais folhosos ou legumes crus), carne, guarnição (vegetais, legumes ou tubérculos cozidos) e sobremesa (frutas ou doces) (Tabela 3 ).

Tabela 1. Distribuição dos usuários do Restaurante Universitário da UNESP/Araraquara de acordo com a faixa etária, o Índice de Massa Corporal (IMC) e o número de refeições consumidas por semana.

\begin{tabular}{|c|c|c|c|c|c|c|}
\hline \multirow{3}{*}{ Usuários } & \multicolumn{6}{|c|}{ Refeições } \\
\hline & \multicolumn{2}{|c|}{$1-6$} & \multicolumn{2}{|c|}{$7-10$} & \multicolumn{2}{|c|}{ Total } \\
\hline & $\mathrm{n}$ & $\%$ & $\mathrm{n}$ & $\%$ & $\mathrm{n}$ & $\%$ \\
\hline \multicolumn{7}{|l|}{ Idade (anos) } \\
\hline$<18$ & 21 & 6,00 & 1 & 2,04 & 22 & 5,51 \\
\hline $18-20$ & 79 & 22,57 & 4 & 8,16 & 83 & 20,80 \\
\hline $20-25$ & 209 & 59,71 & 38 & 77,55 & 247 & 61,91 \\
\hline$>=25$ & 41 & 11,71 & 6 & 12,24 & 47 & 11,78 \\
\hline Total & 350 & 100,00 & 49 & 100,00 & 399 & 100,00 \\
\hline \multicolumn{7}{|l|}{$\operatorname{IMC}\left(\mathbf{k g} / \mathbf{m}^{2}\right)^{*}$} \\
\hline$<18,5$ & 47 & 13,43 & 3 & 6,13 & 50 & 12,53 \\
\hline $18,5-24,99$ & 260 & 74,28 & 41 & 83,67 & 301 & 75,44 \\
\hline$>25-29,99$ & 40 & 11,43 & 4 & 8,16 & 44 & 11,03 \\
\hline$>30$ & 3 & 0,86 & 1 & 2,04 & 4 & 1,00 \\
\hline Total & 350 & 100,00 & 49 & 100,00 & 399 & 100,00 \\
\hline
\end{tabular}

(*) IMC $<18,5=$ baixo peso corporal; IMC de 18,5 a 24,99= peso normal; IMC > $25-29,99=$ sobrepeso; IMC $>30=$ obesidade.

Tabela 2. Dados de peso e altura e recomendação média de ingestão energética e protéica para os usuários do Restaurante Universitário da UNESP/ Araraquara de 18 a 25 anos - 1995.

\begin{tabular}{|c|c|c|c|c|c|c|}
\hline \multirow{3}{*}{ Idade (anos) } & \multirow{3}{*}{ Peso (kg) } & \multirow{3}{*}{ Altura (m) } & \multirow{3}{*}{ TMB* (Kcal/dia) } & $\begin{array}{r}\text { Recor } \\
\text { de Ingestão E }\end{array}$ & $\begin{array}{l}\text { dação } \\
\text { gética (Kcal/dia) }\end{array}$ & \multirow{3}{*}{$\begin{array}{l}\text { Recomendação de } \\
\text { Proteína (g/dia) }\end{array}$} \\
\hline & & & & \multicolumn{2}{|c|}{ Atividade Física } & \\
\hline & & & & Leve & Moderada & \\
\hline \multicolumn{7}{|l|}{ Homens } \\
\hline $18-20$ & $69,7 \pm 9,3$ & $1,78 \pm 0,08$ & 1745,41 & 2792,67 & 2967,20 & 65,43 \\
\hline $20-25$ & $69,7 \pm 9,3$ & $1,78 \pm 0,08$ & 1792,84 & 2868,54 & 3047,83 & 66,25 \\
\hline \multicolumn{7}{|l|}{ Mulheres } \\
\hline $18-20$ & $53,5 \pm 5,6$ & $1,63 \pm 0,05$ & 1282,45 & 1928,18 & 2056,72 & 48,68 \\
\hline $20-25$ & $55,4 \pm 8,6$ & $1,63 \pm 0,07$ & 1310,38 & 1965,57 & 2096,61 & 50,41 \\
\hline
\end{tabular}

*TMB $=$ Taxa Metabólica Basal. 
Tabela 3. Per Capita dos Alimentos e Preparações Oferecidos Por Refeição (Almoço e Jantar) no Restaurante Universitário da UNESP/ Araraquara, São Paulo, 1995.

\begin{tabular}{|c|c|c|}
\hline Cardápio/Dia & Alimentos e Preparações & Peso Líquido (g) \\
\hline & Tomate & 100 \\
\hline & Cenoura crua & 33 \\
\hline & Beterraba crua & 30 \\
\hline & Picadinho de carne & 135 \\
\hline Cardápio 1 & Bolinho de Mandioca & 98 \\
\hline \multirow[t]{3}{*}{ (Dia 1) } & Arroz branco & 269 \\
\hline & Feijão & 124 \\
\hline & Arroz doce & 105 \\
\hline \multirow[t]{4}{*}{ Total } & & 894 \\
\hline & Alface & 26 \\
\hline & Chuchu refogado & 112 \\
\hline & Frango Frito & 99 \\
\hline Cardápio 2 & Arroz & 184 \\
\hline \multirow[t]{2}{*}{ (Dia 2) } & Feijão & 101 \\
\hline & Banana & 97 \\
\hline \multirow[t]{4}{*}{ Total } & & 619 \\
\hline & Alface & 19 \\
\hline & Rúcula & 28 \\
\hline & Purê de batata & 90 \\
\hline Cardápio 3 & Carne de porco frita & 81 \\
\hline \multirow[t]{3}{*}{ (Dia 3) } & Arroz & 168 \\
\hline & Feijão & 120 \\
\hline & Laranja & 201 \\
\hline \multirow[t]{4}{*}{ Total } & & 707 \\
\hline & Chicória & 47 \\
\hline & Berinjela à parmegiana & 123 \\
\hline & Almôndegas fritas (bovina) & 80 \\
\hline Cardápio 4 & Arroz & 180 \\
\hline \multirow[t]{2}{*}{ (Dia 4) } & Feijão & 92 \\
\hline & Salada de Frutas & 122 \\
\hline \multirow[t]{3}{*}{ Total } & & 644 \\
\hline & Alface & 82 \\
\hline & Abobrinha refogada & 109 \\
\hline Cardápio 5 & Bife bovino empanado & 149 \\
\hline \multirow[t]{3}{*}{ (Dia 5) } & Arroz & 204 \\
\hline & Feijão & 91 \\
\hline & Goiabada & 54 \\
\hline Total & & 689 \\
\hline
\end{tabular}

As refeições do RU apresentaram, em média, a seguinte composição química centesimal: $4,74 \%$ de proteínas, $10,84 \%$ de lipídeos, $24,32 \%$ de carboidratos, $3,30 \%$ de fibras, $1,00 \%$ de cinzas e $55,80 \%$ de umidade (Tabela 4). Em média, cada refeição forneceu $33,5 \mathrm{~g}$ de proteínas, 75,6 g de lipídios, 173,6 g de carboidratos, 23,4 g de fibras. O valor energético total médio das refeições foi de 1.509,06 Kcal, apresentando a seguinte média de distribuição de nutrientes: 45,6\% de carboidratos, 45,5\% de lipídeos e 8,9\% de proteínas (Tabela 4).

Pode-se observar que cada refeição supre, em média, mais de $50 \%$ da recomendação de ingestão diária de proteínas para homens. A oferta de energia para homens variou entre $45,1 \%$ e $49,2 \%$. Para as mulheres, cada refeição supre, em média mais de $60,0 \%$ da recomendação de ingestão diária de proteínas. A quantidade média de energia fornecida para mulheres variou entre $65,6 \%$ e $71,3 \%$ (Tabela 5).

\section{DISCUSSÃO}

\section{O perfil da amostra}

Para muitos estudantes, o ingresso na universidade corresponde ao primeiro momento em que eles terão que se responsabilizar por sua moradia, alimentação e gestão de suas finanças, além de administrar o seu tempo e conciliá-lo com os estudos (Eves et al., 1995). A inabilidade para realizar tais tarefas pode resultar em omissão de refeições e consumo de lanches, o que implica inadequação nutricional da alimentação ingerida. No meio estudantil, a omissão de refeições tem sido relacionada inversamente com o nível socioeconômico (Cresswell \& Bushby, 1983). Outra causa que pode explicar a omissão de refeições é a falta de tempo entre as atividades acadêmicas, tanto para preparo das refeições (Eves et al., 1995) quanto para o deslocamento até o restaurante. A existência de restaurante na instituição de ensino pode diminuir o impacto que a mudança do domicílio familiar acarreta e contribuir para a manutenção da saúde do indivíduo.

Quando não se dispõe de dados sobre o perfil da clientela que é atendida, o planejamento dietético é realizado com base em estimativas de peso, altura, idade e nível de atividade física obtidas em estudos realizados na região.

Para o planejamento dietético, é necessário dispor de informações como faixa etária, peso corporal e nível de atividade física. Na falta de informações sobre o peso corporal, é possível estimar o peso corporal ideal desde que se disponha de informações sobre a altura do(s) indivíduo(s).

A altura média dos estudantes que participaram desse estudo é maior do que a média observada pela Pesquisa Nacional Sobre Alimentação e Nutrição (Instituto Nacional..., 1991) na Região Sudeste, para a faixa etária de 18 a 25 anos e, caso essa informação oficial fosse utilizada no planejamento dietético, as demandas de 
Tabela 4. Composição química das refeições (almoço ou jantar) e quantidade de nutrientes oferecidos por refeição (almoço ou jantar) no Restaurante Universitário da UNESP/Araraquara, São Paulo, determinada pela análise da composição química das refeições, 1995.

\begin{tabular}{|c|c|c|c|c|c|c|c|}
\hline \multirow{2}{*}{ Composição Química** } & \multicolumn{5}{|c|}{ Cardápio } & \multirow{2}{*}{\multicolumn{2}{|c|}{ Média $\pm \mathrm{DP}^{*}$}} \\
\hline & 1 & 2 & 3 & 4 & 5 & & \\
\hline Proteínas & 4,6 & 5,0 & 4,9 & 5,2 & 4,0 & 4,74 & 0,47 \\
\hline Lipídeos & 7,9 & 12,5 & 9,5 & 10,1 & 14,2 & 10,84 & 2,50 \\
\hline Carboidratos & 26,6 & 27,4 & 28,0 & 22,8 & 16,8 & 24,32 & 4,67 \\
\hline Fibras & 3,3 & 3,6 & 2,5 & 3,1 & 4,0 & 3,30 & 0,56 \\
\hline Cinzas & 0,8 & 1,1 & 0,9 & 1,2 & 1,0 & 1,00 & 0,16 \\
\hline Umidade & 56,8 & 50,4 & 54,2 & 57,6 & 60,0 & 55,80 & 3,67 \\
\hline \multicolumn{8}{|l|}{ Nutrientes } \\
\hline Energia (Kcal) & $1.751,3$ & $1.498,6$ & $1.534,9$ & $1.306,7$ & $1.453,8$ & $1.509,1$ & $\pm 160,85$ \\
\hline Energia Não-Protéica (Kcal) & $1.586,8$ & $1.374,8$ & $1.396,3$ & $1.172,7$ & $1.343,5$ & $1.374,8$ & $\pm 147,68$ \\
\hline Proteínas (g) & 41,1 & 30,9 & 34,6 & 33,5 & 27,6 & 33,5 & 5,03 \\
\hline Proteínas $(\%)^{* * *}$ & 9,4 & 8,3 & 9,0 & 10,2 & 7,6 & 8,9 & 1,03 \\
\hline Lipídios (g) & 70,6 & 77,4 & 67,2 & 65,0 & 97,8 & 75,6 & $\pm 13,27$ \\
\hline Lipídios (\%) & 36,3 & 46,5 & 39,4 & 44,8 & 60,6 & 45,5 & $\pm \quad 9,36$ \\
\hline Carboidratos (g) & 237,8 & 169,6 & 197,9 & 146,8 & 115,7 & 173,6 & $\pm \quad 46,89$ \\
\hline Carboidratos (\%) & 54,3 & 45,3 & 51,6 & 44,9 & 31,8 & 45,6 & $\pm \quad 8,68$ \\
\hline Fibras (g) & 29,5 & 22,3 & 17,7 & 19,9 & 27,6 & 23,4 & $\pm \quad 5,01$ \\
\hline
\end{tabular}

$(*)$ D.P. $=1$ Desvio-Padrão.

$(* *) \mathrm{g} / 100 \mathrm{~g}$ da refeição.

$\left({ }^{* *}\right)(\%)=$ contribuição porcentual do nutriente para o total de energia da refeição.

Tabela 5. Porcentual do Gasto Energético Total (GET), Suprido pelas Calorias Não-Protéicas, e Porcentual da Recomendação de Ingestão Protéicas Fornecidos por Refeição no Restaurante Universitário da UNESP/Araraquara, Distribuído por Nível de Atividade Física para os Indivíduos do Sexo Masculino e Feminino na Faixa Etária de 18 a 25 anos.

\begin{tabular}{|c|c|c|c|c|c|c|}
\hline \multirow[b]{2}{*}{ Sexo } & \multicolumn{6}{|c|}{ Cardápio } \\
\hline & 1 & 2 & 3 & 4 & 5 & Média \pm D.P.* \\
\hline Masculino & & & & 20 ano & & \\
\hline \multicolumn{7}{|l|}{$\%$ GET } \\
\hline Atividade Leve & 56,8 & 49,2 & 49,9 & 41,9 & 48,1 & $49,2 \pm 5,3$ \\
\hline Atividade Moderada & 53,5 & 46,3 & 47,1 & 39,5 & 45,3 & $46,3 \pm 4,9$ \\
\hline \multirow[t]{2}{*}{ \% Proteínas } & 62,8 & 47,3 & 52,9 & 51,2 & 42,1 & $51,3 \pm 7,7$ \\
\hline & \multicolumn{6}{|c|}{$20-25$ anos } \\
\hline \multicolumn{7}{|l|}{$\%$ GET } \\
\hline Atividade Leve & 55,3 & 47,9 & 48,7 & 40,9 & 46,8 & $47,9 \pm 5,1$ \\
\hline Atividade Moderada & 52,1 & 45,1 & 45,8 & 38,5 & 44,1 & $45,1 \pm 4,8$ \\
\hline \% Proteínas & 62,1 & 46,7 & 52,3 & 50,5 & 41,6 & $50,6 \pm 7,6$ \\
\hline Feminino & \multicolumn{6}{|c|}{$18-20$ anos } \\
\hline \multicolumn{7}{|l|}{$\%$ GET } \\
\hline Atividade Leve & 82,3 & 71,3 & 72,4 & 60,8 & 69,7 & $71,3 \pm 7,6$ \\
\hline Atividade Moderada & 77,1 & 66,8 & 67,9 & 57,0 & 65,3 & $66,8 \pm 7,2$ \\
\hline \multirow[t]{2}{*}{ \% Proteínas } & 84,5 & 63,6 & 71,2 & 68,8 & 56,6 & $68,9 \pm 10,3$ \\
\hline & \multicolumn{6}{|c|}{$20-25$ anos } \\
\hline \multicolumn{7}{|l|}{$\%$ GET } \\
\hline Atividade Leve & 80,7 & 69,9 & 71,0 & 59,7 & 68,3 & $69,9 \pm 7,5$ \\
\hline Atividade Moderada. & 75,7 & 65,6 & 66,6 & 55,9 & 64,1 & $65,6 \pm 7,0$ \\
\hline \% Proteínas & 81,6 & 61,4 & 68,7 & 66,4 & 54,7 & $66,6 \pm 9,9$ \\
\hline
\end{tabular}

(*) D.P. $=1$ Desvio-Padrão.

energia dos usuários do RU da UNESP ficariam subestimadas.

\section{As refeições servidas no restaurante universitário}

Mesmo em se tratando de coletividades consideradas sadias, é imprescindível a adoção de critérios nutricionais no planejamento de cardápios. Nesse aspecto, são possíveis, e cabíveis, pelo menos dois referenciais de análise: o valor energético total das refeições e a distribuição porcentual de energia provenientes de proteínas, lipídeos e glicídeos numa refeição.

Dependendo da forma como se equacionam esses dois referenciais, pode-se chegar à falsa impressão de que um cardápio se encontre com bom nível de adequação. Em outras palavras, por si só o equilíbrio na distribuição dos macronutrientes não indica que tal cardápio esteja equilibrado, pois o seu valor energético total pode exceder 
a recomendação. Da mesma forma, conteúdos de nutrientes abaixo dos porcentuais recomendados não indicam necessariamente a deficiência do nutriente num cardápio. Tal é o que se observa quando se cruzam as informações referentes ao conteúdo de proteínas dos cardápios analisados. Embora o porcentual de energia protéica nas refeições se encontre abaixo dos 10\% e 15\% sugeridos como níveis adequados de consumo, os números absolutos indicam que as duas refeições oferecidas diariamente fornecem, em média, mais de $100 \%$ da recomendação diária de ingestão protéica, mesmo para os indivíduos do sexo masculino, que apresentam o maior requerimento desse nutriente (Tabela 5).

Observa-se que grande parte das refeições de almoço ou jantar oferecidas diariamente no RU da UNESP/ Araraquara contém energia muito além do recomendado. Juntas, as duas refeições fornecem mais do que 100\% da recomendação de ingestão energética para os usuários do sexo feminino e quase a totalidade da recomendação de ingestão energética para os usuários do sexo masculino.

Pelo exposto, conclui-se que os cardápios analisados contêm excesso de proteínas, notadamente aquelas de origem animal. Por exemplo, no cardápio 4 encontra-se presunto, queijo e ovo, juntamente com uma preparação frita de carne bovina (Tabela 3).

As mesmas considerações podem ser feitas quanto à energia proveniente de glicídeos e de lipídeos. Os dados indicam uma grande desproporcionalidade, chegando-se a porcentuais abaixo do recomendado para os primeiros e porcentuais acima da recomendação para os lipídeos, estes últimos os grandes responsáveis pela elevação do valor energético, não apenas aqueles lipídeos contidos em alimentos de origem animal, como também o lipídeo, adicionado via cozimento e fritura (Tabela 3).

A contribuição porcentual dos carboidratos para o consumo de energia dos usuários foi, em média de 45,6\%. O consenso atual é de que o consumo de carboidratos contribua com $55,0 \%$ a $60,0 \%$ do total de energia ingeridas (American..., 1993). Considera-se que o aumento no consumo de carboidratos provoca um aumento no consumo de outros nutrientes como vitaminas, minerais e fibras. Além disso, a ingestão de alimentos ricos em carboidratos pode diminuir o consumo da energia total ingerida diariamente se esses alimentos substituírem alimentos ricos em gorduras (Bidlack \& Wang, 1995).

A alimentação oferecida no RU fornece, em média, 23,4 g de fibras por refeição ou, aproximadamente, 46,8 g/dia. Como o valor recomendado para a ingestão de fibras dietéticas é de 24 g/dia (World Health..., 1990), a alimentação oferecida durante o período do estudo continha um teor elevado de fibras.

A contribuição porcentual dos lipídeos para o consumo de energia dos usuários foi, em média de 45,5\%. As orientações atuais indicam que os lipídeos não devem contribuir com mais do que $30 \%$ da ingestão energética total (World Health..., 1990; Sociedade..., 1993). As refeições apresentaram um porcentual de lipídeos totais maior do que o recomendado.
Além dos conhecidos danos à saúde provocados por uma alimentação hiperenergética, hiperlipídica e hiperprotéica, cabe lembrar a relevância econômica da adequação dos cardápios, uma vez que os maiores custos das refeições geralmente se associam à utilização de alimentos "nobres", geralmente de origem animal, de concentrações protéicas e lipídicas elevadas. Sob esse enfoque, pode-se afirmar que o redimensionamento dos alimentos e das preparações oferecidas no restaurante em questão possibilitaria o acesso dos usuários a uma alimentação nutricionalmente equilibrada e com um impacto econômico menor para os usuários e para a instituição.

\section{REFERÊNCIAS BIBLIOGRÁFICAS}

AMERICAN DIABETES ASSOCIATION. Nutritional recommendations and principles for individuals with diabetes melito. Diabetes Care, New York, v.16, p.22-29, 1993.

ASSOCIATION OF OFFICIAL AGRICULTURE CHEMISTS. Official methods of analysis. 14.ed. Washington DC, 1965. 955p.

BEATON, G.H. Nutritional assessment of observed nutrient intake: an interpretation of recent requirement reports. Advances in Nutrition Research, New York, n.7, p.101-128, 1985.

BIDLACK, W.R., WANG, W. Nutrition requirements of the elderly. In: MORLEY, J.E., GLICK, Z., RUBENSTEIN, L.Z. Geriatric Nutrition. 2.ed. New York : Raven Press, 1995. p.25-49.

CRESSWELL, J., BUSHBY, A. Dietary patterns of third year Secundary Schoolgirls in Glasgow. Human Nutrition, London, v.37A, n.4, p.301-306, 1983.

EVES, A., KIPPS, M., PARLETT, G. Undernourished students - myth or reality? Nutrition and Food Science, Bradford, n.2, p.5-11, 1995.

FAUSTO, M.A., GARCIA JÚNIOR, J.R., ESTEVES, S.A. Avaliação nutricional, utilizando o índice de massa corporal (IMC), e identificação dos usuários do restaurante universitário (RU) da UNESP/ Araraquara, São Paulo. In: JORNADA FARMACÊUTICA INTERNACIONAL DA UNESP, 42., Araraquara, 1995. Anais... Araraquara : UNESP, 1995. p.A6.

FOOD AGRICULTURE ORGANIZATION. Necesidades de energía y de proteinas. Ginebra, 1985.219p (Informes Tecnicos, n.724).

INSTITUTO NACIONAL DE ALIMENTAÇÃO E NUTRIÇÃO. Condições nutricionais da população brasileira: adultos e idosos. Pesquisa Nacional sobre Saúde e Nutrição. Brasília: Ministério da Saúde, 1991. 39p.

NATIONAL RESEARCH COUNCIL (USA). Recommended Dietary Allowances. 10.ed. Washington DC, 1989. 284p.

SOCIEDADE BRASILEIRA DE CARDIOLOGIA. Consenso brasileiro sobre dislipidemias: detecção, avaliação e tratamento. Arquivos Brasileiros de Cardiologia, São Paulo, v.61, p.1-13, 1993. Suplemento 1.

WORLD HEALTH ORGANIZATION. Diet, nutrition, and the prevention of chronic diseases. Geneva, 1990. (Technical Report Series, n.797).

WORLD HEALTH ORGANIZATION. Physical satatus: the use and interpretation of anthropometry. Geneva, 1995. 452p. (Technical Report Series, n. 854).

Recebido para publicação em 9 de novembro de 1999 e aceito em 30 de novembro de 2000. 